\title{
Measuring foraging activity in bumblebee nests: a simple nest-entrance trip recorder
}

\author{
P. G. Kevan ${ }^{1}$, E. Cooper ${ }^{2}$, A. Morse ${ }^{1}$, J. P. Kapongo ${ }^{1,3}$, L. Shipp ${ }^{3}$ \& S. Khosla ${ }^{4}$ \\ 1 Department of Environmental Biology, University of Guelph, Guelph, ON, Canada \\ 2 Radix Controls, Oldcastle, ON, Canada \\ 3 Agriculture and Agri-Food Canada, Greenhouse and Processing Crops Research Centre, Harrow, ON, Canada \\ 4 Ontario Ministry of Agriculture and Food, Harrow, ON, Canada
}

\begin{abstract}
Keywords
Bombus, actograph, forager, greenhouse,

pollination, pollinator

Correspondence

Peter G. Kevan (corresponding author), Department of Environmental Biology, University of Guelph, Guelph, ON, Canada N1G 2W1. E-mail: pkevan@uoguelph.ca
\end{abstract}

Received: April 8, 2008; accepted: August 13, 2008.

doi: 10.1111/j.1439-0418.2008.01338.x

\begin{abstract}
We describe a new, electronic, apparatus for measuring the activity of bumblebees as they fly from and to their nests. The bee activity recorder (BAR) works on the principle that bees leaving and returning to their nest crawl through a tube equipped with infrared emitters and detectors so that when the beam is interrupted by the passage of a bee, the event is recorded as either an exit or an entry. Tests of BARs indicate that they are highly accurate, BAR counts and visual counts highly correlated with an almost one-to-one correspondence. We suggest that BARs can be used for recording the foraging activities of bumblebees through nest exit and entry counts in many practical and research applications.
\end{abstract}

\section{Introduction}

Bumblebees of various species have become increasingly important as commercially available pollinators, especially in the greenhouse industry around the world (Fisher and Pomeroy 1989; Banda and Paxton 1991; Kevan et al. 1991; van Ravestijn and van der Sande 1991; Dogterom et al. 1998; Velthuis and van Doorn 2006). Although these bees work on flowers efficiently and bring about levels of pollination that exceed those eventuating from automatic self-pollination (Shipp et al. 1994; Porporato et al. 1995; Ercan and Onus 2003; Roldan Serrano and Guerra-Sanz 2006) and human-assisted pollination (Kevan et al. 1991; Chen and Hsieh 1996; Dogterom et al. 1998; Pressman et al. 1999; Dag and Kammer 2001; Morandin et al. 200la; Dasgan et al. 2004; Palma et al. 2008a,b), it is important to assess the activities of bumblebees under greenhouse conditions to optimize the bees' activity levels, pollination efficiencies (Morandin et al. 200lb) and losses from greenhouses (Morandin et al. 2001c). For example, the nature of the coverings of the houses influences activity (Morandin et al. 2002), as can regimes of temperature (Kwon and Saeed 2003), humidity and light. Understanding seasonal (Koide and Hayashi 1993; Al-Attal et al. 2003; Sabara et al. 2004) activity and daily (Lee et al. 2003) pollination patterns is useful for management planning. Monitoring foraging activity has revealed the effects of pesticides (Tasei et al. 2001; Alarcon et al. 2005), diseases (Whittington and Winston 2003; Gegear et al. 2005, 2006; Otterstatter et al. 2005) and drifting of workers between colonies (Birmingham and Winston 2004; Birmingham et al. 2004) in bumblebees' floral visitations. Different species of pollinators may or may not show different patterns of activities and pollination effectiveness (Asada and Ono 1996; Whittington and Winston 2004; Li et al. 2006). The behaviour of greenhouse pollinators is influenced by the kinds of crops being grown and their floral characters (Roldan-Serrano and Guerra-Sanz 2005; Lefebvre and Pierre 2006). Also, the newer use of bumblebees as disseminators of biocontrol agents 
against insect pests and plant pathogens in greenhouses (Al-mazra'awi et al. 2006; Kevan et al. 2007, 2008) requires monitoring for possible influences on pollination efficiency.

The most commonly used way of monitoring has been by direct human observation, but having personnel devoted to counting bumblebees leaving and entering their nests is expensive, tedious and prone to error. Morandin et al. (2001a,c, 2002) effectively employed a portable counter that fitted easily to the entrance of commercially available bumblebee nests to record the exits and entries of the resident bumblebees. The data from that recorder did not discriminate between exits and entries, and could not be downloaded into a computer. Nevertheless, from that innovation, we developed improved technology and developed the bee activity recorder (BAR) described herein.

\section{Description of the Bee Activity Recorder}

Our device uses infrared (IR) beams to detect the passages (exits and entrances) of bees through a tunnel (fig. 1), which is attached to the entrance into the bee nest (fig. 2). The IR beams operate at a wavelength of $950 \mathrm{~nm}$ so are invisible to bees. Two IR beams are used to detect the direction (in or out) of bee movement (fig. 1) by detecting the order of disruptions by the bees. The IR emitters are on opposite walls of the tunnel so as to not interfere with each other. This also allows the distance between the emitters to be small. The distance between emitters is less than the average length of a bumblebee so that the emitters respond to the activity of only one bee at a time. The inside diameter of the tunnel is such that only one bee can pass through at a time. The inside of the sensor head is
Fig. 1 Diagram of the sensing tunnel.
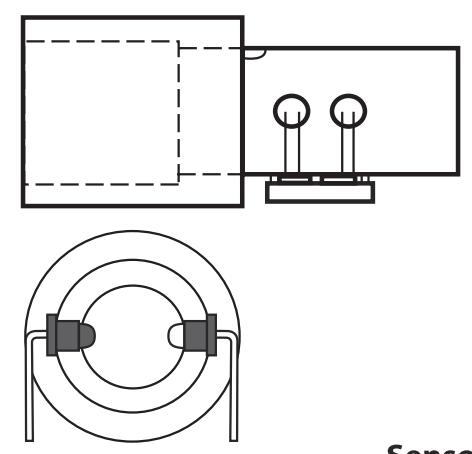

-

Sensor head

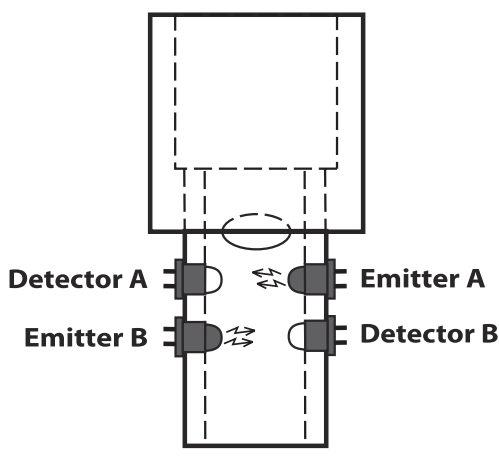

Fig. 2 Bee activity recorder in place on a bumblebee domicile.

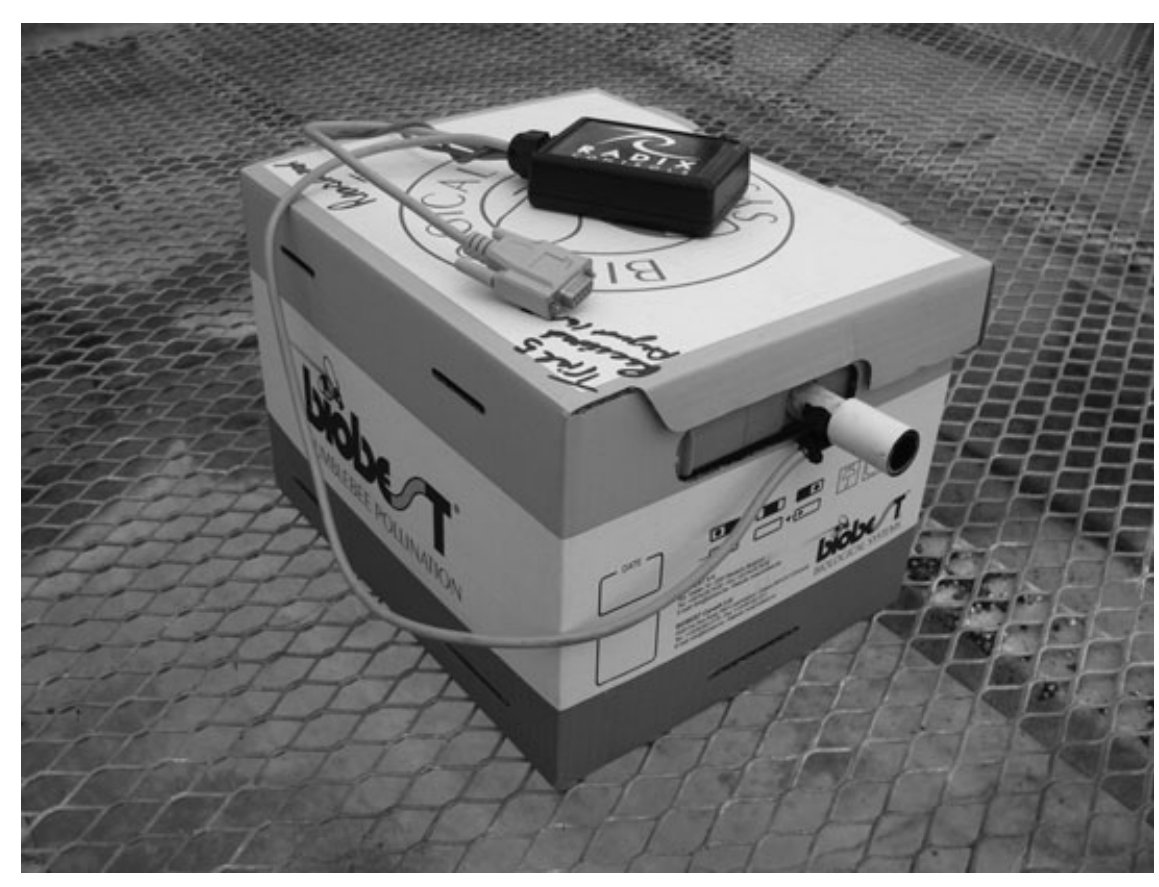


painted a flat black to reduce light reflections from the sky and sun hitting the IR detectors. The wire leads are coated with rubber to protect them from the environment.

Each BAR has an external sensor head (the entrance and exit tunnel to the nest) holding the IR emitters and detectors, a box of electronics (microcontroller housing coupled with an adjustable electronic clock), two power cables [each with either a socket (receptacle) or a plug] and an RS232 standard computer-communication connector. The plug connects to the DC power supply either on a DC power adapter or another BAR's power cable. The RS232 (DB9) connector is used to collect (download) the stored data to a computer for analyses. Future designs of the BAR could use wireless or ethernet communication for data collection. The BAR is powered by $12 \mathrm{~V}$ DC, wall mounted, power supply adapter to allow use of mains electrical power. The AC power in some locations may fluctuate greatly so we used an uninterruptable power supply (UPS) to filter and regulate the mains power. UPSs are inexpensive and readily available and one UPS can be used to power several chains of BARs. The BAR can be use individually (fig. 3a) or up to five can be connected together in series (fig. 3b) on one power supply. Connecting the BAR power cable into the power receptacle of the preceding BAR makes a chain of BARs. The arrangement that we developed was selected to make operational assembly as simple as possible and to keep manufacturing costs as low as possible.

Table 1 presents the information recorded by the BAR that is used to determine whether or not the bee is leaving or entering the nest through the tunnel.

The BAR can save 262140 sample periods with each sample period containing 15 'in' and 15 'out'

Table 1 The movement of a bee entering or leaving the hive through the sensor head produces five sequential conditions in which one, both or neither of the two IR beams may be blocked from their detectors by the moving bee

$$
\begin{array}{ll}
\text { Valid movements } & \\
\ln & \text { Out }
\end{array}
$$

$\begin{array}{lllllllllll}\text { Detector B } & 1 & 0 & 0 & 1 & 1 & 1 & 1 & 0 & 0 & 1 \\ \text { Detector A } & 1 & 1 & 0 & 0 & 1 & 1 & 0 & 0 & 1 & 1\end{array}$

By tracking the order of detection and lack of detection in the two detectors, the counter is able to differentiate between a bee exiting or entering the hive.

1, IR light path clear; 0, IR beam blocked.

$\mathrm{IR}$, infrared.

(a)

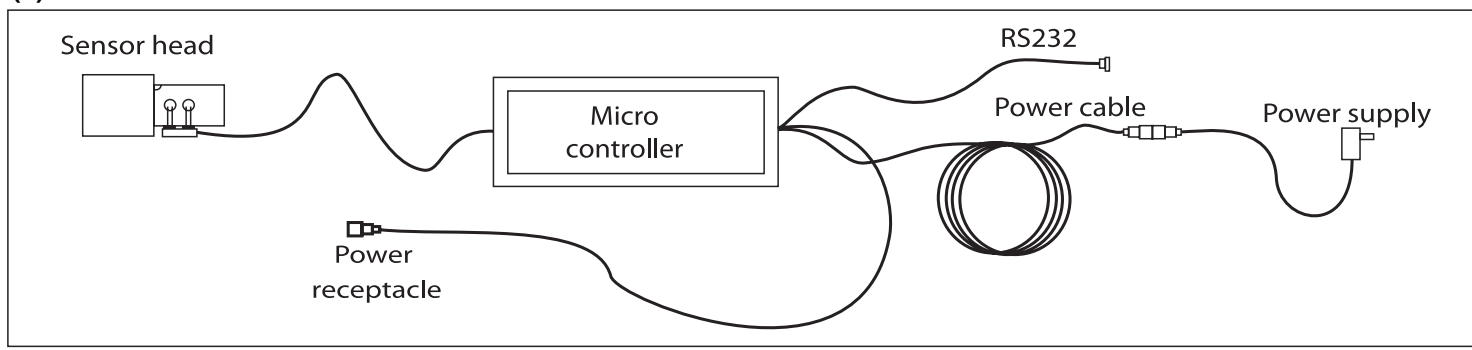

(b)

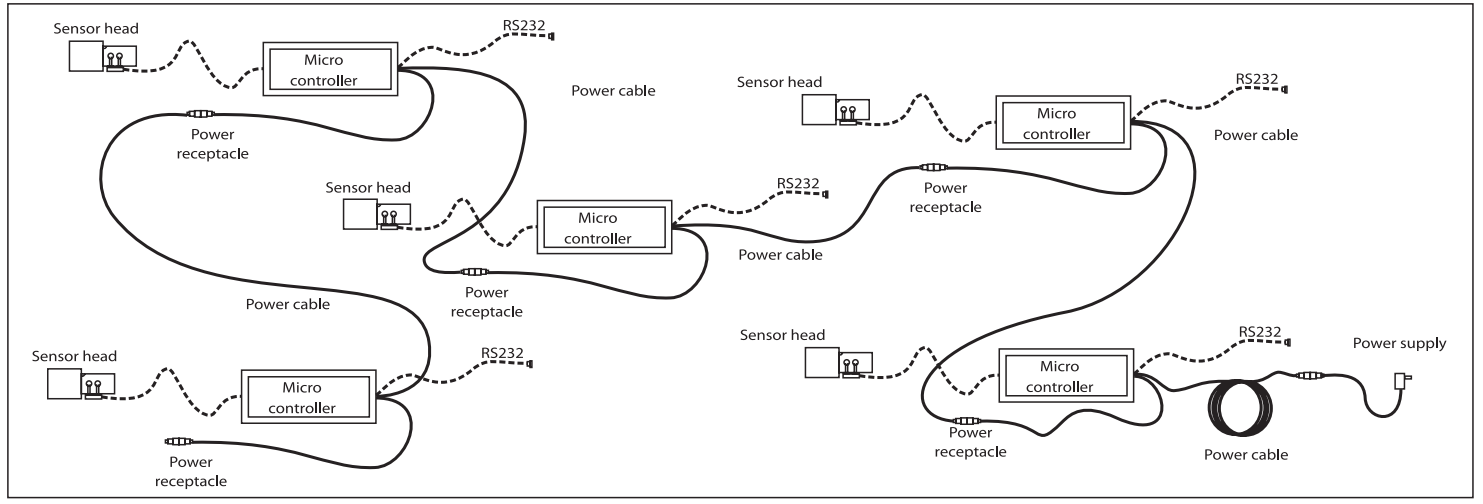

Fig. 3 Diagram of bee activity recorders used as single units (a) or connected in series (b). The bumblebee domiciles are not shown. 
events. The sample period duration can range from 2 to $5 \mathrm{~s}$. That gives the BAR a total capacity of 7864200 events (in and out) covering a range of 615 days. If the BAR looses power, it restarts and overwrites any saved data.

The counters that we have designed and constructed can be custom made for about \$195 US. Although people with appropriate technical skills could make their own BARs, it is beyond the scope of this paper to provide a listing of all the components needed to do so.
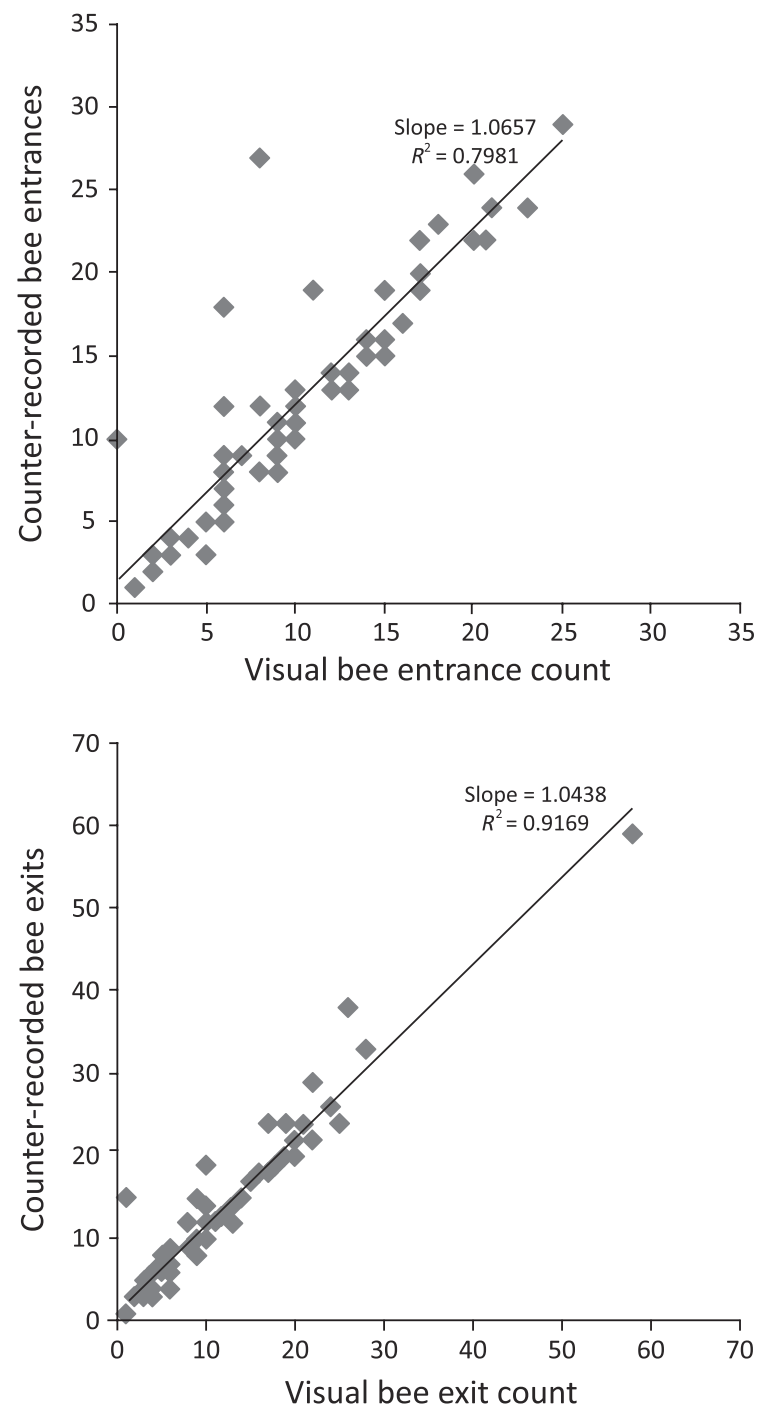

\section{Testing the BARs}

Although the counter counts exactly and only the number of times the light beam is interrupted. It is known that bumblebees, as other bees, may venture to the exit of the nest only to turn round and return to the interior. It is also well known that colonially nesting bees may post-guards at the nest entrances. Both behaviours would result in counts additional to those reflecting foraging trips. Our counters were designed so that only one bee at a time could easily
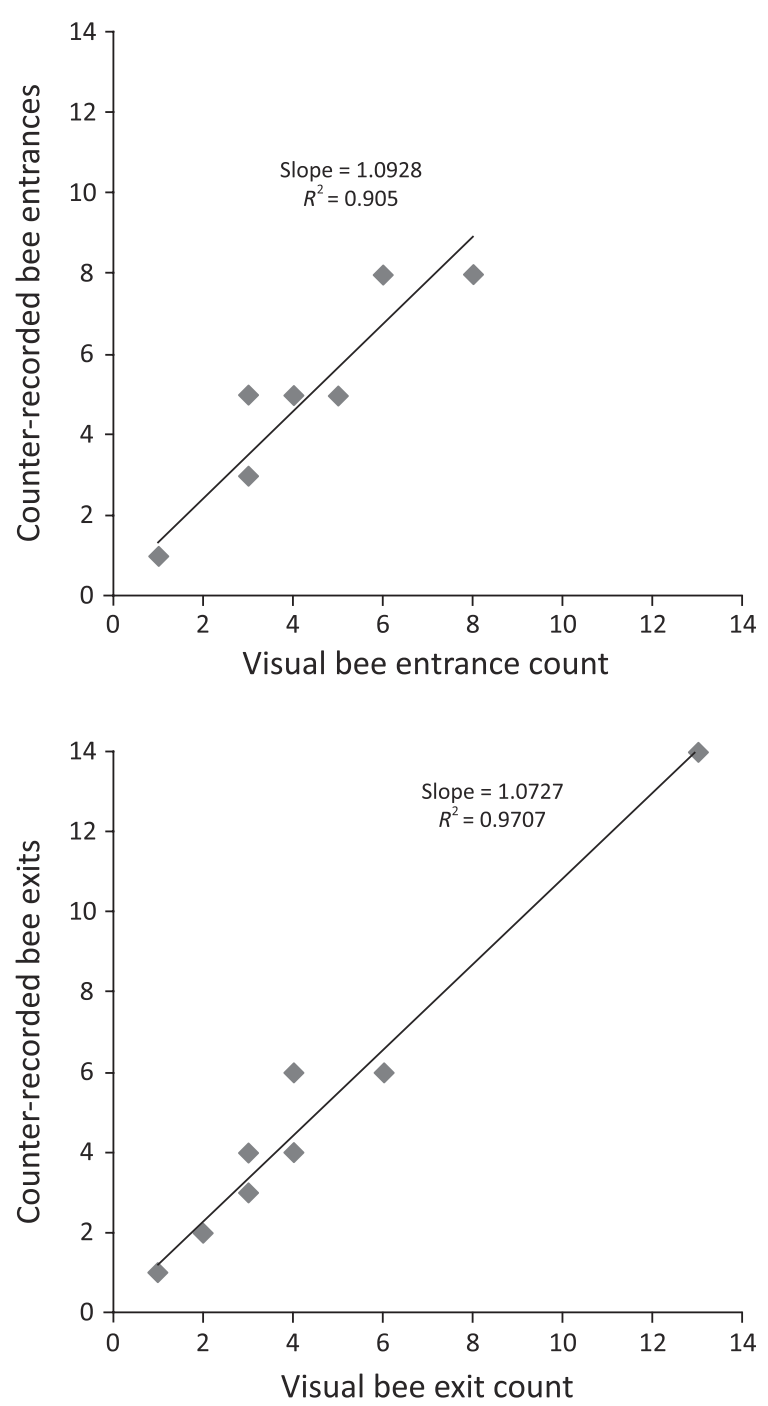

Fig. 4 Graphs on the left represent results of comparisons of simultaneously obtained bee activity recorder counts and direct observation of entrances (a) and exits (b) from three bumblebee colonies each deployed in a different commercial greenhouse in Leamington, Ontario (2006), those on the right present results from one colony deployed in the experimental greenhouses at the Greenhouse and Processing Crops Research Centre in Harrow, Ontario (2006). Data were gathered between 09:00 and 15:00 hours North American Eastern Daylight Savings Time under conditions of natural daylight, except as attenuated by the greenhouse coverings. 


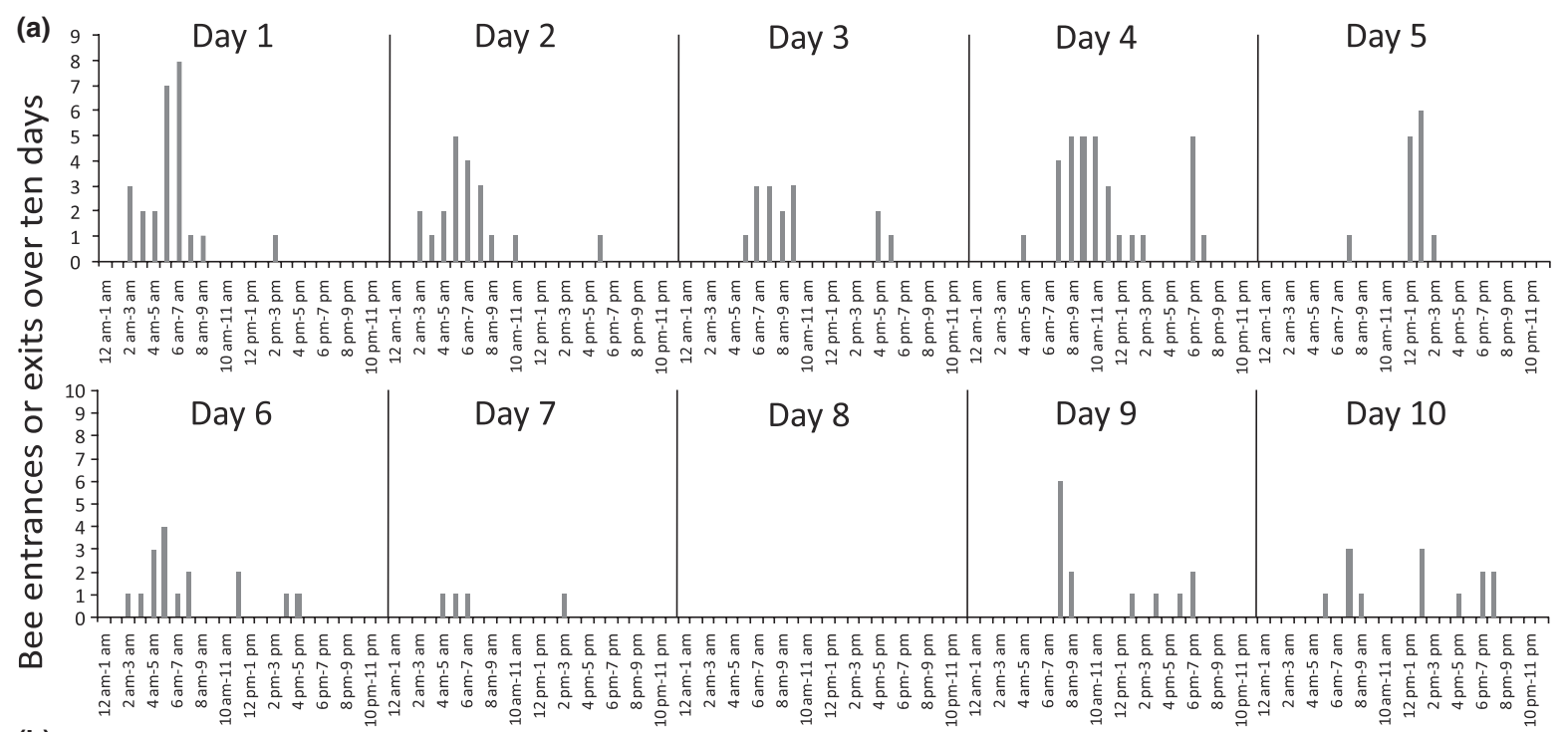

(b)

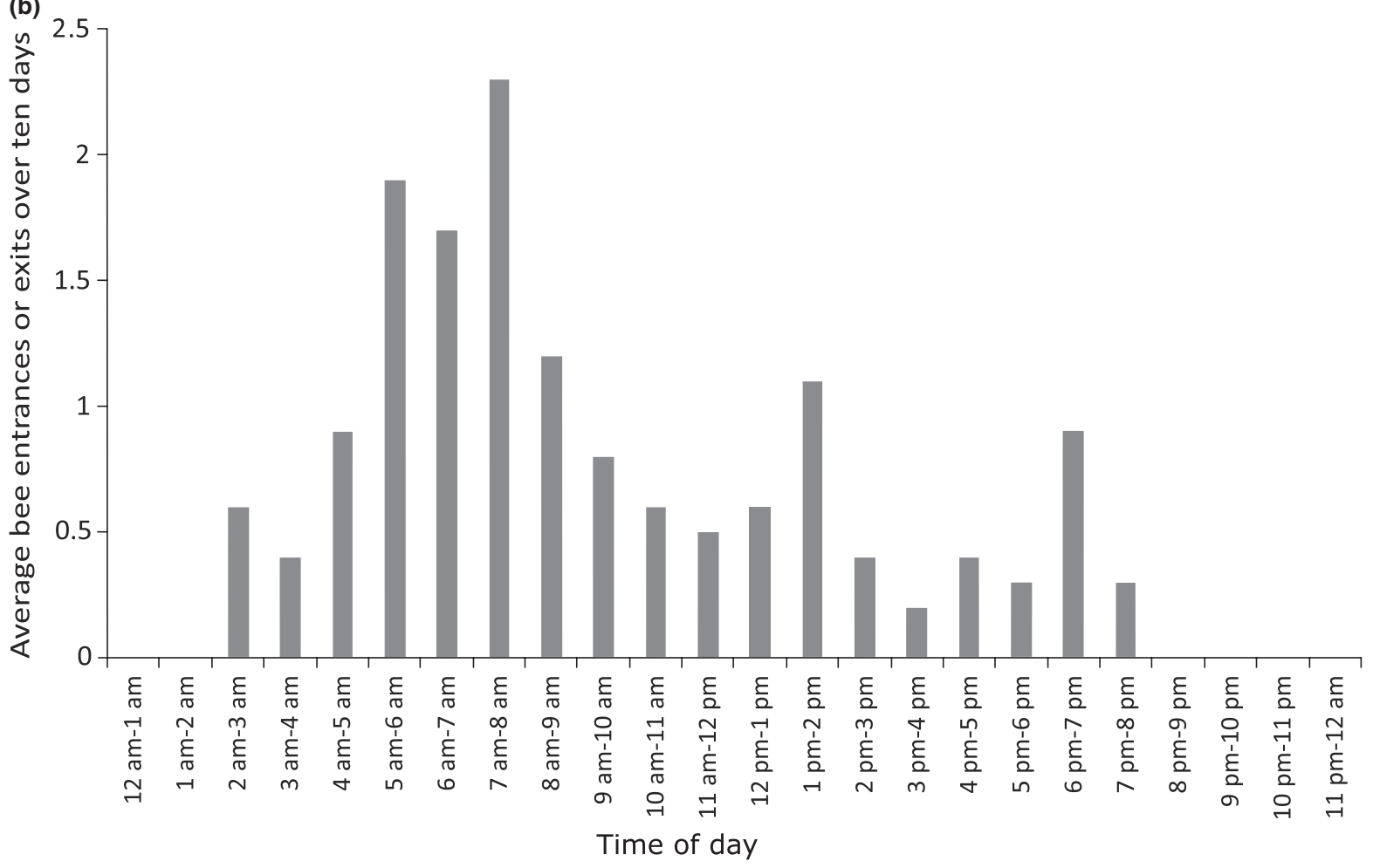

Fig. 5 Activity records (exits per hour) from a single bumblebee colony over 10 days (1-10 June 2007) (a) deployed in the experimental greenhouses at the Greenhouse and Processing Crops Research Centre in Harrow, Ontario. (b) Average daily activity of that colony over the same 10 days. On days 1 and 2 , the very early activity (before dawn), shown for an example of need to confirm the nature of the counts obtained, may reflect the bees' being disturbed by noise and vibration of greenhouse vents opening and closing.

walk through the sensor head. Thus, the counts we obtained were of individual bees breaking the light beam. To test the accuracy of the counters, we recorded bumblebees actually leaving and entering the colonies in greenhouses illuminated by natural daylight except as attenuated by the coverings [see Morandin et al. (2002) for effects of greenhouse coverings on foraging activity] for standard periods (up to $30 \mathrm{~min}$ ) over several days between 09:00 and 15:00 hours North American Eastern Daylight 
Savings Time. We then compared the actual foraging counts with the counts obtained by the counter. The slopes of the graphs are not different from one, but reflect two minor sources of error: observer error, especially in recording entries in the commercial greenhouse (fig. 4, top left) and bees that did not actually exit but were recorded in the tunnel of the BAR. Both sources of error result in higher counts by the BAR than would be recorded by direct observation to account for the slopes' being slightly more than 1.0 .

Given the level of accuracy and reliability of the BARs that we have described, longer-term records of bumblebee activity can be analysed. Figure 5(a) presents 10 days of records for a single bumblebee colony and fig. 5(b) the average daily activity for that colony recorded for those 10 days. It is beyond the intent of this paper to discuss the early morning (pre-dawn) activity recorded for two of those days (fig. 5). Nevertheless, on-site monitoring indicated that the results presented are unusual and perhaps represent a bee, or bees, became active at the exit in response to disturbance. Records showed that greenhouse vents opened and closed at about that time on those days and that the times between 'exit' and 'entrance' were only a few seconds, i.e. not foraging trips. The records for the other 8 days show that the bees became active at dawn, except on cloudy days.

Although our results attest to the accuracy of the BARs in operation, we recommend that anyone using them calibrate them through direct observation. Different species of bumblebees, and other bees behave differently at the entrances to their nests.

\section{Acknowledgements}

We thank Improved Farming Systems and Practices Initiative, Pest Management Centre, Agriculture and Agri-Food Canada for financial assistance. Also the authors thank E. Armstrong, G. Mosey, M. Pachal, K. Wang and M. Whitfield for technical assistance.

\section{References}

Alarcon AL, Canovas M, Senn R, Correia R, 2005. The safety of thiamethoxam to pollinating bumble bees (Bombus terrestris L.) when applied to tomato plants through drip irrigation. Commun. Agric. Appl. Biol. Sci. 70, 569-579.

Al-Attal YZ, Nazer IK, Kasrawi MA, 2003. Monitoring bumblebee (Bombus terrestris L.) activity in pollinating tomatoes (Lycopersicon esculentum Mill) under plastichouses in Jordan. Dirasat Agric. Sci. 3, 149-155.
Al-mazra'awi MS, Shipp L, Broadbent B, Kevan PG, 2006. Biological control of Lygus lineolaris (Hemiptera: Miridae) and Frankliniella occidentalis (Thysanoptera: Thripidae) by bombus impatiens (Hymenoptera: Apidae) vectored Beauveria bassiana in greenhouse sweet pepper. Biol. Control 37, 89-97.

Asada S, Ono M, 1996. Crop pollination by Japanese bumblebees, Bombus spp (Hymenoptera: Apidae): tomato foraging behavior and pollination efficiency. Appl. Entomol. Zool. 3, 581-586.

Banda HJ, Paxton RJ, 1991. Pollination of greenhouse tomatoes by bees. Acta Hortic. 228, 194-198.

Birmingham AL, Winston ML, 2004. Orientation and drifting behaviour of bumblebees (Hymenoptera: Apidae) in commercial tomato greenhouses. Can. J. Zool. 82, 52-59.

Birmingham AL, Hoover SE, Winston ML, Ydenberg RC, 2004. Drifting bumble bee (Hymenoptera: Apidae) workers in commercial greenhouses may be social parasites. Can. J. Zool. 82, 1843-1853.

Chen C-T, Hsieh F-K, 1996. Evaluation of pollination efficiency of the bumblebee (Bombus terrestris L.) on greenhouse tomatoes. Zhonghua Kunchong 16, 167175.

Dag A, Kammer Y, 2001. Comparison between the effectiveness of honey bee (Apis mellifera) and bumble bee (Bombus terrestris) as pollinators of greenhouse sweet pepper (Capsicum annuum). Am. Bee J. 141, 447-448.

Dasgan HY, Ozdogan AO, Kaftanoglu O, Abak K, 2004. Effectiveness of bumblebee pollination in anti-frost heated tomato greenhouses in the Mediterranean basin. Turkish J. Agric. Forestry 28, 73-82.

Dogterom MH, Matteoni JA, Plowright RC, 1998. Pollination of greenhouse tomatoes by the North American Bombus vosnesenskii (Hymenoptera: Apidae). J. Econ. Entomol. 91, 71-75.

Ercan N, Onus AN, 2003. The effects of bumblebees (Bombus terrestris L.) on fruit quality and yield of pepper (Capsicum annuum L.) grown in an unheated greenhouse. Isr. J. Plant Sci. 51, 275-283.

Fisher RM, Pomeroy N, 1989. Pollination of greenhouse muskmelons by bumble bees (Hymenoptera, Apidae). J. Econ. Entomol. 82, 1061-1066.

Gegear RJ, Otterstatter MC, Thomson JD, 2005. Does parasitic infection impair the ability of bumblebees to learn flower-handling techniques? Anim. Behav. 70, 209-215.

Gegear RJ, Otterstatter MC, Thomson JD, 2006. Bumblebee foragers infected by a gut parasite have an impaired ability to utilize floral information. Proc. R. Soc. B Biol. Sci. 273, 1073-1078.

Kevan PG, Straver WA, Offer M, Laverty TM, 1991. Pollination of greenhouse tomatoes by bumble bees in Ontario. Proc. Entomol. Soc. Ont. 122, 15-19. 
Kevan PG, Sutton J, Shipp L, 2007. Pollinators as vectors of biocontrol agents - the B52 story. In: Biological control: a global perspective. Ed. by Vincent C, Goettel MSG, Lazarovits G, CAB International, Wallingford, Oxford, 319-327.

Kevan PG, Kapango J-P, Al-mazra'awi MS, Shipp L, 2008. Honey bees, bumble bees, and biocontrol: new alliances between old friends. In: Bees in agricultural ecosystems. Ed. by Pitts-Singer TL, James R, Oxford University Press, Oxford, 65-79.

Koide T, Hayashi G, 1993. Studies on the using of bumblebees (Bombus terrestris) in fruit vegetables I: behavior of foraging in greenhouse and effects of bumblebees on fruit quality and setting of cherry tomato. Res. Bull. Aichi-ken Agric. Res. Cent Issue 25, 165-170.

Kwon YJ, Saeed S, 2003. Effect of temperature on the foraging activity of Bombus terrestris L. (Hymenoptera: Apidae) on greenhouse hot pepper (Capsicum annuum L.). Appl. Entomol. Zool. 38, 275-280.

Lee SB, Bae TW, Kim SE, Yoon HJ, Lee ML, Chae Y, 2003. The influence of over foraging, and pollinating activities on tomato fruits by a Korean native bumblebee, Bombus ignitus S. (Hymenoptera: Apidae) in cherry-tomato houses. Korean J. Appl. Entomol. 42, 293-300.

Lefebvre D, Pierre J, 2006. Spatial distribution of bumblebees foraging on two cultivars of tomato in a commercial greenhouse. J. Econ. Entomol. 99, 1571-1578.

Li J-L, Peng W-J, Wu J, An J-D, Guo Z-B, Tong Y-M, Huang J-X, 2006. Strawberry pollination by Bombus lucorum and Apis mellifera in greenhouses. Acta Entomol. Sin. 49, 342-348.

Morandin LA, Laverty TM, Kevan PG, 2001a. Bumble bee (Hymenoptera: Apidae) activity and pollination levels in commercial tomato greenhouses. J. Econ. Entomol. 94, 462-467.

Morandin LA, Laverty TM, Kevan PG, 2001b. Effect of bumble bee (Hymenoptera: Apidae) pollination intensity on the quality of greenhouse tomatoes. J. Econ. Entomol. 94, 172-179.

Morandin LA, Laverty TM, Kevan PG, Khosla S, Shipp L, 2001c. Bumble bee (Hymenoptera: Apidae) activity and loss in commercial tomato greenhouses. Can. Entomol. 133, 883-893.

Morandin LA, Laverty TM, Gegear RJ, Kevan PG, 2002. Effect of greenhouse polyethelene covering on activity level and photo-response of bumble bees. Can. Entomol. 134, 539-549.

Otterstatter MC, Gegear RJ, Colla SR, Thomson JD, 2005. Effects of parasitic mites and protozoa on the flower constancy and foraging rate of bumble bees. Behav. Ecol. Sociobiol. 58, 383-389.

Palma G, Quezada-Euan JJ, Melendez-Ramirez V, Irigoven J, Valdovinos-Nuez GR, Rein M, 2008a.
Comparative efficiency of Nannotrigona perilampoides, Bombus impatiens (Hymenoptera: Apoidea), and mechanical vibration on fruit production of enclosed habanero pepper. J. Econ. Entomol. 101, 132-138.

Palma G, Quezada-Euan JJG, Reyes-Oregel V, Melendez $\mathrm{V}$, Moo-Valle H, 2008b. Production of greenhouse tomatoes (Lycopersicon esculentum) using Nannotrigona perilampoides, Bombus impatiens and mechanical vibration (Hym.: Apoidea). J. Appl. Entomol. 132, 79-85.

Porporato M, Pinna M, Manino A, Marletto F, 1995. Pollination of sweet pepper in greenhouses by Bombus terrestris (L.) and Apis mellifera L. Apicoltore Mod. 86, 99-112.

Pressman E, Shaked R, Rosenfeld K, Hefetz A, 1999. A comparative study of the efficiency of bumble bees and an electric bee in pollinating unheated greenhouse tomatoes. J. Hortic. Sci. Biotechnol. 74, 101-104.

van Ravestijn W, van der Sande J, 1991. Use of bumblebees for the pollination of glasshouse tomatoes. Acta Hortic. 228, 204-212.

Roldan Serrano A, Guerra-Sanz JM, 2006. Quality fruit improvement in sweet pepper culture by bumblebee pollination. Sci. Hortic. (Amsterdam) 110, 160-166.

Roldan-Serrano AS, Guerra-Sanz JM, 2005. Reward attractions of zucchini flowers (Cucurbita pepo L.) to bumblebees (Bombus terrestris L.). Eur. J. Hortic. Sci. 70, 23-28.

Sabara HA, Gillespie DR, Elle E, Winston ML, 2004. Influence of brood, vent screening, and time of year on honey bee (Hymenoptera: Apidae) pollination and fruit quality of greenhouse tomatoes. J. Econ. Entomol. 97, 727-734.

Shipp JL, Whitfield GH, Papadopoulos AP, 1994. Effectiveness of the bumble bee, Bombus impatiens $\mathrm{Cr}$. (Hymenoptera, Apidea) as a pollinator of greenhouse sweet pepper. Sci. Hortic. 57, 29-39.

Tasei J-N, Ripault G, Rivault E, 2001. Hazards of imidacloprid seed coating to Bombus terrestris (Hymenoptera: Apidae) when applied to sunflower. J. Econ. Entomol. 94, 623-627.

Velthuis HHW, van Doorn A, 2006. A century of advances in bumblebee domestication and the economic and environmental aspects of its commercialization for pollination. Apidologie 37, 421-451.

Whittington R, Winston ML, 2003. Effects of Nosema bombi and its treatment fumagillin on bumble bee (Bombus occidentalis) colonies. J. Invertebr. Pathol. 84, 54-58.

Whittington R, Winston ML, 2004. Comparison and examination of Bombus occidentalis and Bombus impatiens (Hymenoptera: Apidae) in tomato greenhouses. J. Econ. Entomol. 97, 1384-1389. 